Article

\title{
Development of an Assistant System of Clean Intermittent Catheterization for Neurogenic Bladder Dysfunction Patients
}

\author{
Chun-Ming Huang ${ }^{1}{ }^{(\mathbb{C}}$, Jhih-Cheng Wang ${ }^{2,3}$, Jia-Jin Jason Chen ${ }^{1}$, Yi-Chun $\mathrm{Du}^{4, * \mathbb{C}}$ and \\ Jing-Yi Chen ${ }^{4}$ \\ 1 Department of Biomedical Engineering, National Cheng Kung University, Tainan 701, Taiwan; \\ P88991123@mail.ncku.edu.tw (C.-M.H.); chenjj@mail.ncku.edu.tw (J.-J.J.C.) \\ 2 Division of Urology, Department of Surgery, Chi Mei Medical Center, Tainan 710, Taiwan; \\ tratadowang@gmail.com \\ 3 Center for General Education, Southern Taiwan University of Science and Technology, Tainan 710, Taiwan \\ 4 Department of Electrical Engineering, Southern Taiwan University of Science and Technology, \\ Tainan 710, Taiwan; 4a127047@stust.edu.tw \\ * Correspondence: terrydu@stust.edu.tw; Tel.: +886-6-253-3131 (ext. 3321)
}

Received: 14 January 2019; Accepted: 1 April 2019; Published: 5 April 2019

\begin{abstract}
Clean intermittent catheterization (CIC) is one of the methods currently used to prevent overdistention of the bladder in patients with neurogenic bladder dysfunction (NBD). It is also helpful in preventing urinary tract infection and retaining the function of the bladder. Voiding diary and social behavior are necessary for the patients to maintain their physical and mental health, nevertheless there are currently no good assistant systems to help them achieve these goals. In this study, we propose a CIC assistant system with the functions of recording and tracking the voided volume and accessible lavatory. The aim of this study is to assess the effects from the 12 patients who joined the proposed system. Information collected from participants included their demographics, past medicals, injury characteristics, current and past bladder managements, and any NBD related complications. The results indicate that most patients felt relieved that they could know the voided volume and track their history easily. Moreover, the accessible lavatory function of the proposed system could reduce time consumption by $43.1 \%$ in finding the suitable lavatory, thus the desire and willingness of patients to travel increased from $25 \%$ to $75 \%$ after using the system. The proposed system could help doctors with clinical diagnoses, and help patients to understand more about the history of their catheterization volume and time period. This study provided essential information and design for future investigation.
\end{abstract}

Keywords: clean intermittent catheterization (CIC); neurogenic bladder dysfunction (NBD); assistant system; accessible lavatory function; quality of life

\section{Background}

Vehicular accidents and falls are the primary causes of spinal cord injuries (SCI), which are often accompanied by a second injury. Within the SCIs, falls among the elderly are increasing with the aging population [1]. One of the most frequent complications of SCI are urinary tract infections (UTIs). Among SCI patients, $80 \%$ suffer from bladder dysfunction, out of which, $36 \%$ or more will have to be hospitalized because of complications [2,3]. Having lost the sensation of bladder filling, patients could not determine when and how to start urination autonomously. Consequently, indwelling catheters (IC) or CIC becomes an option to empty the bladder. Nevertheless, IC can cause bladder atrophy due to long-term poor contraction. Filth accumulated in the folds of the bladder wall can also lead 
to cystitis, bladder stones, smaller capacities, low-compliance bladder, low blood flow to the bladder wall, infections, and high mortality [4-6]. The odor and unpleasant appearance of urinal collection bags also arouse the feelings of inferiority and isolation.

If the bladder of a CIC patient is overdistended before the catheterization is performed again, there would be an over-expansion of the bladder wall and the intravesical pressure would rise rapidly, resulting in a low bladder blood flow, a low-compliance bladder, and a dangerous situation for the patient. If the bladder holds more than $300 \mathrm{~mL}$ of urine, it will increase infection rate $4-5$ times $[7,8]$. As a consequence of negligence and misjudgment of clinical infections, treatment delay is very likely to happen and thus increase hospitalization days and costs [9]. CIC performed with voiding diary helps restore and retain the function and compliance of the bladder, as well as release the intravesical pressure and increase the blood flow of the bladder wall, enabling the bladder to perform antibacterial activities and lessen the chance of complications [10-17]. Voiding diary is a simple and primary tool used to understand urinary tract function and assess urinary symptoms, with a view to providing doctors with sufficient data for an appropriate clinical diagnosis. However, diary record with pen and paper is time-consuming and it may cause frequent omissions and increase the patients' burden [18-21]. Furthermore, SCI patients need social support to overcome depression and neurosis derived from fear and self-imposed pressure after a sudden injury [22,23].

The purpose of this study is to develop a personalized assistant system for CIC patients with NBD. This system, combined with the accessible lavatory function, can automatically record individual urine voiding volume, compute bladder health status, and give feedback, so as to keep the patients from holding urine as much as possible.

\section{Methods}

This study developed a CIC assistant system for bladder care that includes a CIC assistant device and cloud system for bladder health feedback and accessible lavatory function, as shown in Figure 1. The CIC assistant system automatically records each voided volume of the patient and is liable for statistics and feedback. The report is uploaded to the medical cloud database for future reference. The accessible lavatory function offers a solution to patients who are forced to hold their urine because they cannot find a decent toilet in time whenever they are outside.

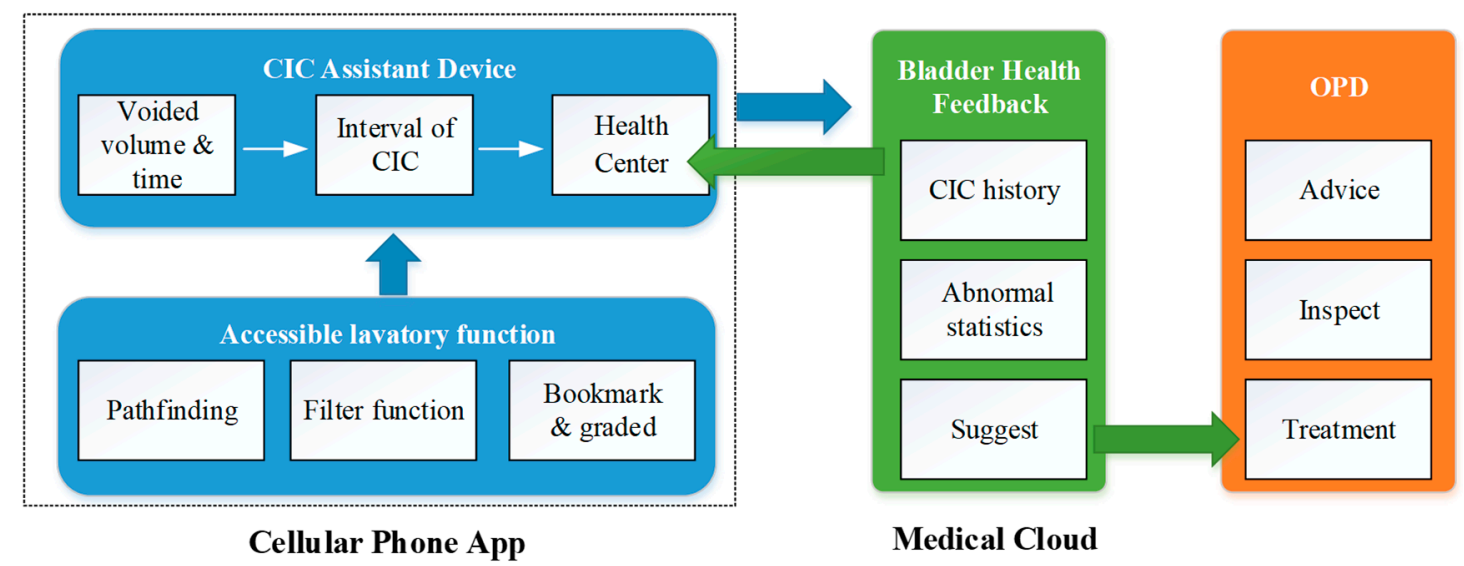

Figure 1. The structure of the personalized assistant system of clean intermittent catheterization (CIC). OPD: outpatient department.

\subsection{CIC Assistant Device}

This study established an inexpensive urine pot measuring device which suits all models of urine pots and containers. The sensor module weighs the urine pot through the voltage change after catheterization. The value collected shows the voided volume. This amount also resembles the bladder's capacity as the CIC cleans up the entire storage. Signals are transmitted through the 
blue-tooth wireless technology to the user's cellular phone, then simultaneously saved and shown on the screen. The data are then recorded, accumulated, and stored, both in the cellular phone and the medical cloud database. The voided volume is compared to different tolerance levels $[4,24,25]$ and is shown with different colors on the diagram (Table 1). The color green means normal bladder condition, but other colors mean that the patient may need to adjust water intake.

Table 1. Voided volume range and color bar of each clean intermittent catheterization (CIC) show on app.

\begin{tabular}{cc}
\hline Volume (c.c.) & Color \\
\hline$\leq 150$ & Blue \\
$151 \sim 399$ & Green \\
$400 \sim 549$ & Yellow \\
$550 \sim 699$ & Red \\
$\geq 700$ & Purple \\
\hline
\end{tabular}

This study utilized the ATmega 328P-AU (Atmel Corporation, San Jose, CA, USA) as the microchip processor for data transmission in the urinal volume assessment device through weighing measurement. The HX711 (AVIA Semiconductor, Xiamen, China) was used as the 24 bit AC/DC converter of the load cell amplifier. It conveyed the power as electronic signals and then delivered them to the controller. The advantages were higher noise tolerance and high response speed. Moreover, HC-05 2.4 Ghz was chosen as the Bluetooth module because of its low dissipation ( $8 \mathrm{~mA})$ and completeness in indoor remote data transmission $(8 \mathrm{M})$. The structure of the urine pot measuring module, as seen in Figure 2, indicated the amount of voided volume. Data were transmitted to the user's cellular phone through Bluetooth. The CIC assistant device shown in Figure 3 is portable, installable on ready-made urine pots, and rechargeable through micro-USB. A battery volume of $800 \mathrm{mAh}$ allows for $4 \mathrm{~h}$ of continuous power supply.

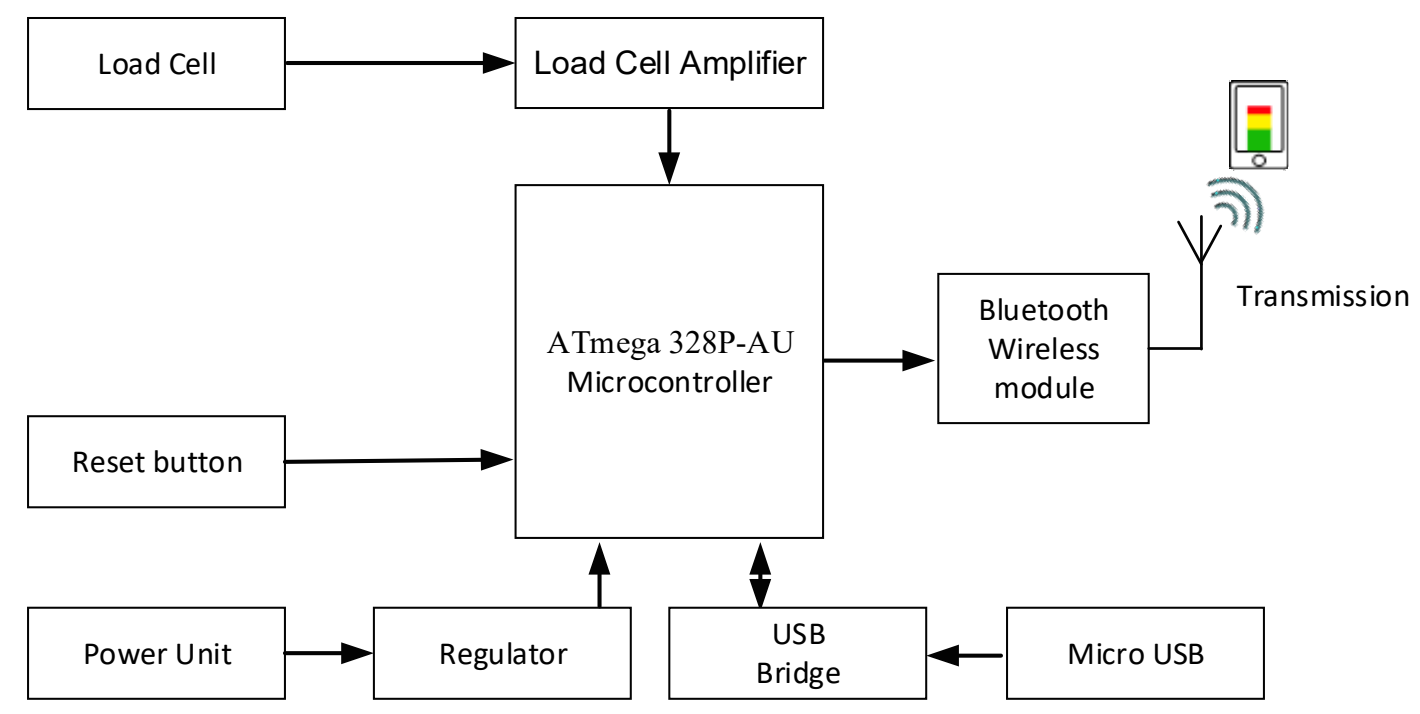

Figure 2. Structure of urine pot measuring module. 


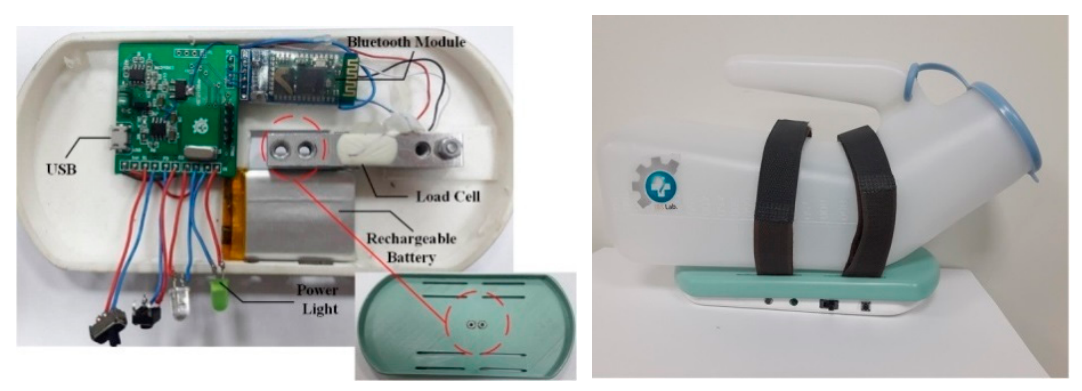

Figure 3. The measuring module of CIC assistant device exterior-view (left) and with container (right).

Based on the study, the app recorded the user's voided volume, the exact time of voiding, and the interval of the CIC. Alerts are given immediately when the result is abnormal, as shown in the following rules.

A. Voided volume $\leq 150 \mathrm{~mL}$ per unit time. The app calculates the interval between two catheterizations. If the time is less than $2 \mathrm{~h}$, the app will suggest postponing the act as frequent catheterization brings harm to the urethra. The app records the results without an alert for an interval of 2 to $4 \mathrm{~h}$. When the time exceeds $4 \mathrm{~h}$, the app detects insufficient water intake and will suggest that the patient drink more water.

B. Voided volume 151 to $399 \mathrm{~mL}$ per unit time. The app considers that this is a good condition and will not give an alert.

C. Voided volume 400 to $549 \mathrm{~mL}$ per unit time. The app calculates the interval between two catheterizations. If the time is less than $2 \mathrm{~h}$, the app will suggest cutting down on water intake by $200 \mathrm{cc}$ and postponing the catheterization to $2 \mathrm{~h}$ later. The app records the results without alert for an interval of 2 to $4 \mathrm{~h}$. When the time exceeds $4 \mathrm{~h}$, the app considers it as a normal situation and will not give an alert.

D. Voided volume 550 to $699 \mathrm{~mL}$ per unit time. The app calculates the interval between two catheterizations. If the time is less than $2 \mathrm{~h}$, the app will suggest cutting down on water intake by $250 \mathrm{cc}$ and postponing the catheterization to $2 \mathrm{~h}$ later. The app suggests cutting down water intake by $200 \mathrm{cc}$ or postponing the catheterization to $3 \mathrm{~h}$ later for an interval of 2 to $4 \mathrm{~h}$. When the time exceeds $4 \mathrm{~h}$, the app suggests cutting down water intake by $150 \mathrm{cc}$ or postponing the catheterization to $4 \mathrm{~h}$ later.

E. Voided volume $\geq 700 \mathrm{~mL}$ per unit time. The app calculates the interval between two catheterizations. If the time is less than $2 \mathrm{~h}$, the app will suggest cutting down a huge amount of water intake and performing catheterization $1 \mathrm{~h}$ later. For results falling in between 2 to $4 \mathrm{~h}$, the app will advise the patient to drink $50 \mathrm{cc} / \mathrm{h}$ and catheterization after two hours. When the time exceeds $4 \mathrm{~h}$, the app proposes a fluid intake of $100 \mathrm{cc} / \mathrm{h}$ and catheterization $3 \mathrm{~h}$ later.

\subsection{Feedback on Bladder Health}

This app calculated the total number of abnormal output in a month and concluded the statistics according to the voided volume recorded in the system. Table 2 shows the suggestion classification on the app's health center. The app not only provided suggestions regarding bladder understanding and management, but also invited the patients to recover the wellbeing of their urinal system. By doing so, cases of UTIs, infections, and medical resources could be lessened [26].

To provide doctors with more data for more accurate diagnosis, the patients' personal information, including age, gender, time since injury, level of injury, bladder sensation, and numbers of infections are recorded in a database management system, as seen in Figure 4. The history of catheterization for each patient is also uploaded to the cloud server and saved as encryption data. After logging in, the outpatient department (OPD) doctor writes down a prescription and gives advice for the 
succeeding examinations or treatments [27]. As for the Internet connections, the history of the voided volume is stored in the app and transmitted to the server via WiFi or 4G.

Table 2. CIC urination statistics and suggestion on the health center.

\begin{tabular}{ccc}
\hline Volume (mL/CIC) & Frequency/Month & Suggest \\
\hline \multirow{2}{*}{$\leq 150$} & $<10$ & Normal \\
& $>10$ & Drink more water, reduce the frequency of catheterization \\
\hline \multirow{2}{*}{$400 \sim 549$} & $<10$ & Normal \\
& $>10$ & Moderate water volume intake, suggest same frequency of catheterization \\
\hline $550 \sim 699$ & $<5$ & Normal \\
& $>5$ & Drink less water, catheterize once more if water intake goes beyond limit \\
& $>10$ & Advise to do check-up at a hospital, possibility of UTIs \\
\hline & $<5$ & Normal \\
& $>5$ & Immediate inspection for UTIs \\
& $>10$ & Immediate inspection of the urinary system, recommend kidney ultrasonography \\
\hline
\end{tabular}

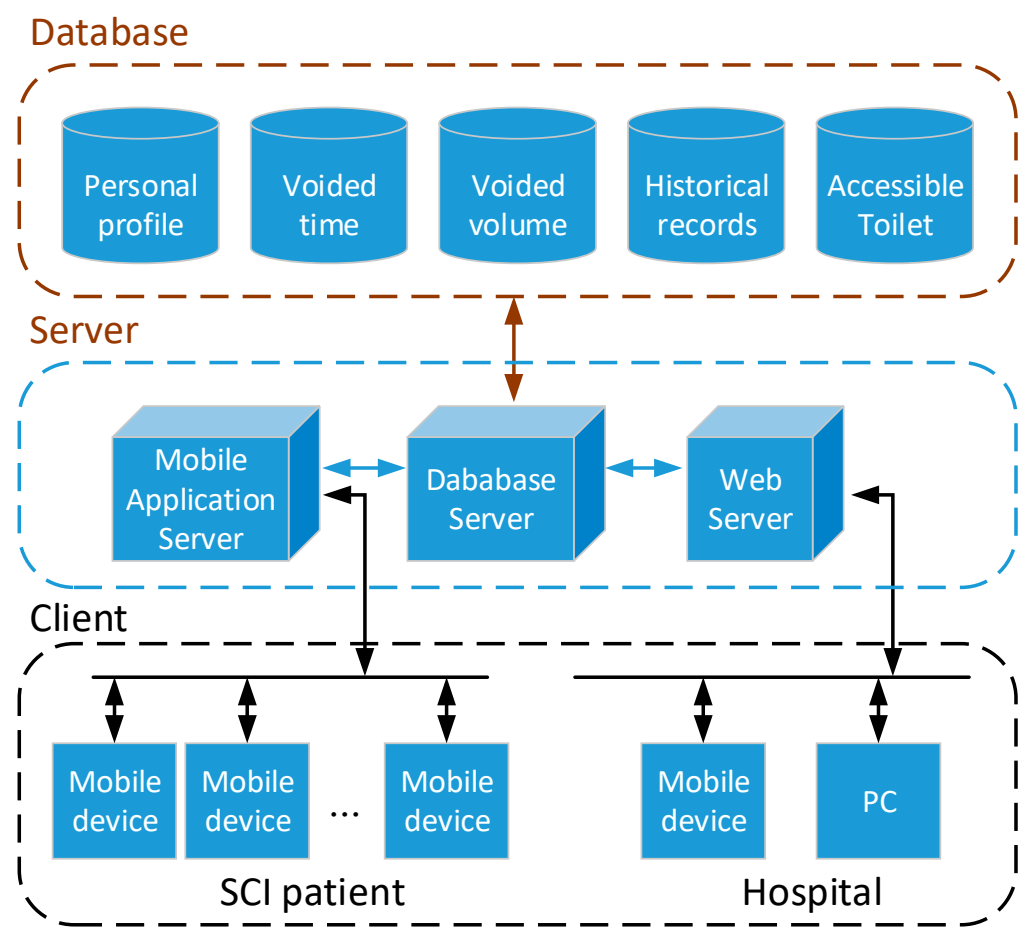

Figure 4. Relational database management system.

\subsection{Accessible Lavatory Function}

NBD CIC patients have no bladder filling sensation [28] and were often afraid to move around, especially in an unfamiliar environment because they could not easily find a decent, accessible lavatory [29]. An accessible lavatory function that could calculate the shortest route to the nearest and the most suitable lavatory was also proposed in the system made by the study. Its algorithm was set according to the research of Bast et al. [30,31]. The navigator function provides the information of all nearby accessible lavatories including location, condition, and estimated time of arrival. A filter function was also added, such as a washbasin, which is very important for CIC patients when they are disinfecting and cleaning the catheter. This function also allows patients to bookmark the location and grade each user experience, because a neat environment could decrease infection rate when they are in the process of CIC. 


\section{Results}

There were 12 patients, with CIC bladder management strategy, recruited as the subjects of the research under the specification of the Institutional Review Board (IRB): 10510-003 of Chi Mei Medical Center. Table 3 is recognized as an overview of their demographic and clinical features. The age of patients ranged from 21 to 51 years old with an average of 39.25 years old. The recruited patients were interpreted by clinicians and their cytometric capacity, intravesical pressure and compliance were in the normal range, and their bladder pressure was highly correlated with the volume $[4,24,32]$. Level of injury primarily fell on C (58.4\%) and $\mathrm{T}(33.3 \%)$. The majority of these patients chose to conduct CIC indoors $(91.7 \%)$ and $33.3 \%$ of them kept a record of each voided volume, while $66.7 \%$ were in fear of excess voided volume. This study observed that only $25 \%$ of the patients returned for OPD follow-up after one year or more.

Table 3. Demograghic and clinical features $(n=12)$.

\begin{tabular}{cc}
\hline Age (yr) & Mean 39.25 (Range 21-51) \\
\hline Mean time since injury (yr) & Mean 6.5 (Range 0.5-25) \\
\hline $\begin{array}{c}\text { Gender }(\%) \\
\text { Male /female }\end{array}$ & $75 / 25$ \\
\hline $\begin{array}{c}\text { Level of injury }(\%) \\
\text { C/T/L/S }\end{array}$ & $58.4 / 33.3 / 8.3 / 0$ \\
\hline $\begin{array}{c}\text { Location of CIC }(\%) \\
\text { Indoor/Outdoor }\end{array}$ & $31.7 / 8.3$ \\
\hline $\begin{array}{c}\text { Record CIC volume }(\%) \\
\text { Yes /No }\end{array}$ & $66.7 / 33.3$ \\
\hline $\begin{array}{c}\text { Fear excess urine volume }(\%) \\
\text { Yes / No }\end{array}$ \\
\hline
\end{tabular}

CIC assistant system automatically records and uploads the precise amount of catheterization and statistics, as shown in Figure 5. Figure 6 shows the regressive curve of urine volume measurement between CIC assistant device and graduated cylinder, its R-square was 0.99 . Records are displayed on the app on the client's screen. After collection and calculation, the feedback system reminds patients to modify their lifestyles or to return to the hospital for further inspection in order to reduce UTIs and other complications. Furthermore, the accessible lavatory function shows the shortest route to the most suitable lavatory after patients enter their requirements. This saves considerable time for patients when searching for a toilet. Table 4 represents the frequency in a month for voided urine volume $>550 \mathrm{~mL}$ of 12 patients with CIC strategy. Fewer SCI patients with bladder sensations encountered even more problems of excess voided volume in comparison with those without bladder sensations.

Table 4. Voided urine volume $\geq 550 \mathrm{~mL}$ per month $(n=12)$.

\begin{tabular}{cccccc}
\hline \multirow{2}{*}{ Bladder Sensation, $\mathbf{n}(\%)$} & \multicolumn{5}{c}{ Time } \\
\cline { 3 - 6 } & & $\mathbf{0}$ & $\mathbf{1} \mathbf{5}$ & $\mathbf{6 \sim 9}$ & $\mathbf{1 0 \sim}$ \\
\hline Yes & 42 & 2 & 2 & 1 & 0 \\
No & 58 & 0 & 1 & 4 & 2 \\
\hline
\end{tabular}




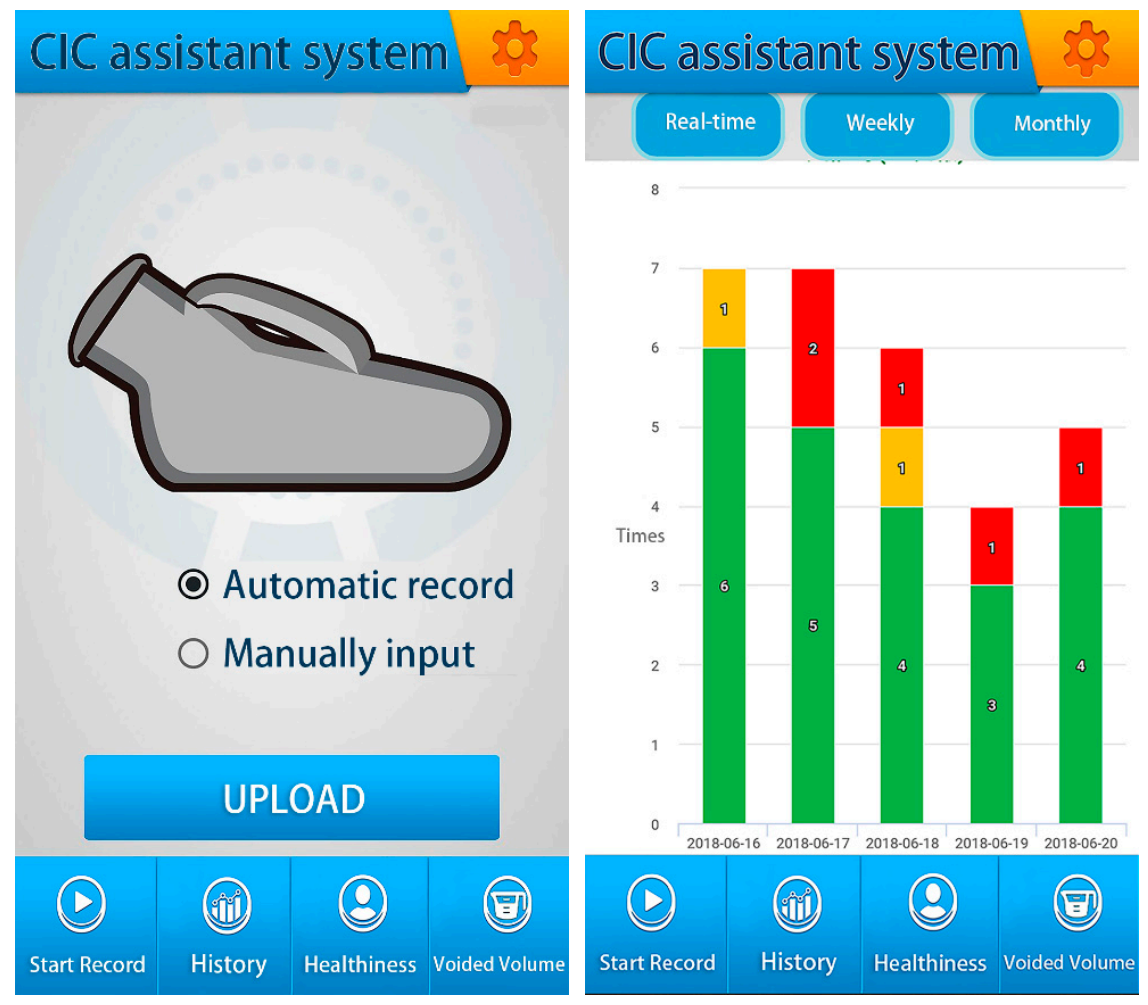

Figure 5. Urine volume record and statistics in the CIC assistant device (left) and the different color bars measuring the quantity of CIC volume level as in Table 1 (right).

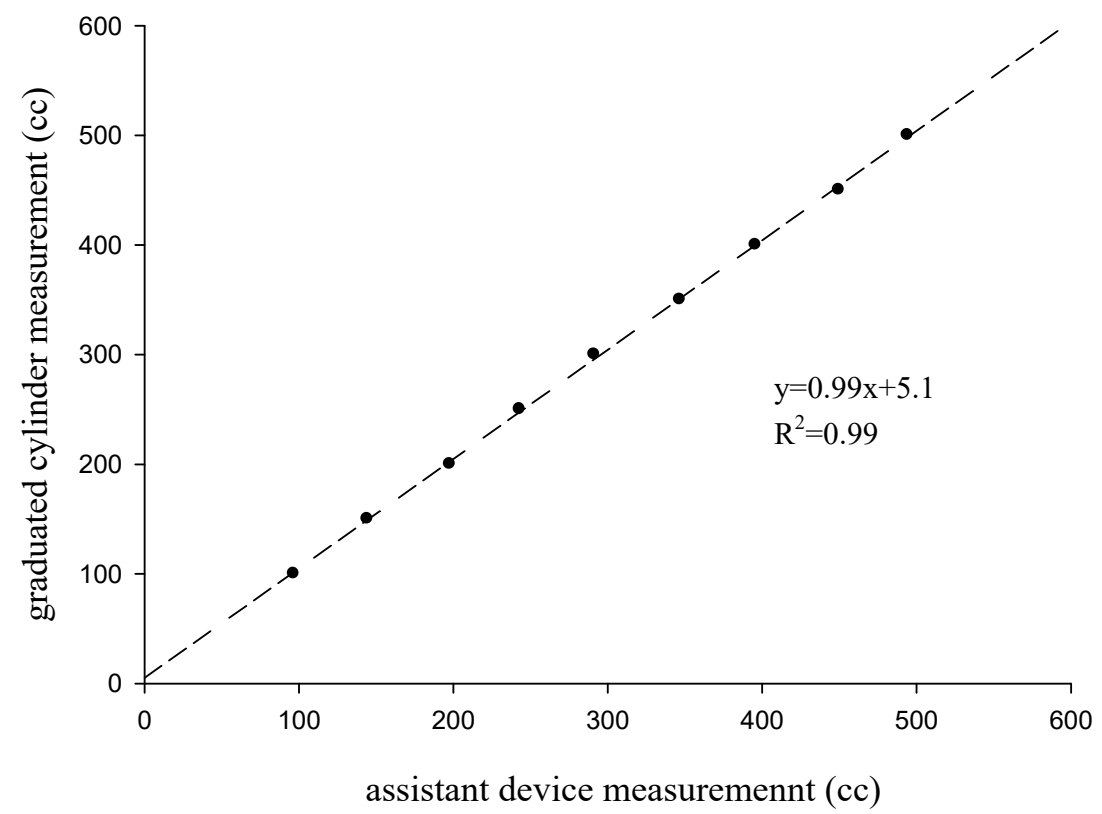

Figure 6. The regressive curve of urine volume measurement between CIC assistant device and graduated cylinder.

Figure 7 shows how the accessible lavatory function in the app provided information regarding all the nearby accessible lavatories with a filter function. Patients could also add a new lavatory on our cloud system after verification. The results of patients looking for a lavatory in an unfamiliar environment with this function were shown by the following data: unfamiliar $43.1 \%$, semi-familiar $27.2 \%$, and familiar $17.6 \%$. The time spent searching for a lavatory independently was $22.5 \mathrm{~min}$, $15.8 \mathrm{~min}$, and $13.6 \mathrm{~min}$ respectively. By using the accessible lavatory function, the arrival time decreased 
to $12.8 \mathrm{~min}, 11.5 \mathrm{~min}$, and $11.2 \mathrm{~min}$ respectively (Table 5). SCI patients with CIC were inclined to perform CIC at home, or at least indoors, because of the inconvenience of searching for an accessible lavatory in an open area (Table 3). A reduced motivation for going out could lead to social detachment, psychological disorders, and an unpleasant lifestyle [19]. Table 6 indicates the improvement of patient intention, from $25 \%$ to $75 \%$, through the aid of the accessible lavatory function. It is beneficial in expanding the patient's social contact while at the same time promoting the maintenance of a healthy state of mind.
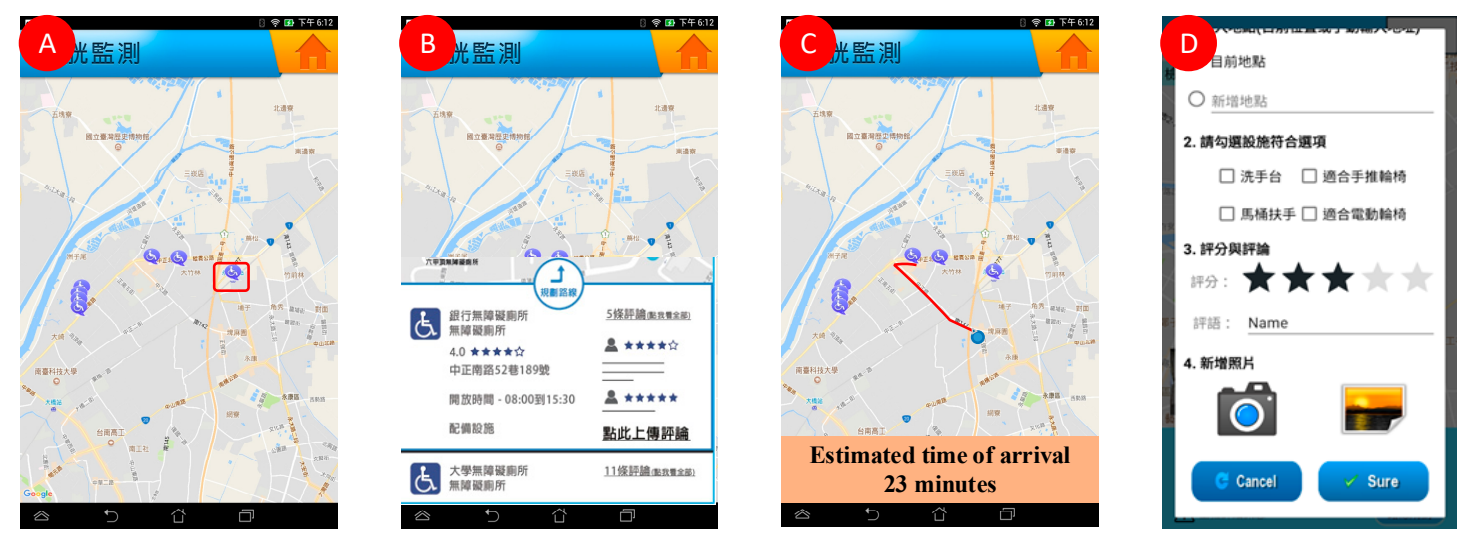

Figure 7. Accessible lavatory function of (A) list all the nearby accessible lavatories, (B) detailed information of each lavatory, (C) estimated time of arrival and (D) the interface of adding a new lavatory.

Table 5. Accessible toilet arrival time in different environments without/with accessible lavatory function.

\begin{tabular}{cccc}
\hline Environment & w/o (Range)/min & w/ (Range)/min & Time Reduction (\%) \\
\hline Unfamiliar & $22.5(18 \sim 35)$ & $12.8(8 \sim 17)$ & 43.1 \\
Semi-familiar & $15.8(9 \sim 25)$ & $11.5(8 \sim 16)$ & 27.2 \\
Familiar & $13.6(9 \sim 16)$ & $11.2(7 \sim 17)$ & 17.6 \\
Average & $17.3(9 \sim 35)$ & $11.8(7-17)$ & 29.3 \\
\hline
\end{tabular}

Unfamiliar: Never been; Semi-familiar: Been 1-3 times; familiar: Been $>4$ times

Table 6. Intention to travel.

\begin{tabular}{ccccc}
\hline \multirow{2}{*}{ Questions } & \multicolumn{2}{c}{ Travel Alone \% } & \multicolumn{2}{c}{ Travel with Accessible Lavatory Function \% } \\
\cline { 2 - 5 } & Yes & No & Yes & No \\
\hline Inconvenient to find a suitable accessible toilet & 91.7 & 8.3 & 0 & 100 \\
Travel willingness & 25 & 75 & 75 & 25 \\
\hline
\end{tabular}

\section{Discussions and Conclusion}

The research developed a CIC assistant system of intermittent catheterization for neurogenic bladder dysfunction patients to record their voided volume and make suggestions. The patients with CIC bladder management strategy were recruited. The cytometric capacity, intravesical pressure, and bladder compliance of these patients were in the normal range $\left(>40 \mathrm{~mL} / \mathrm{cm} \mathrm{H}_{2} \mathrm{O}\right)$, and the bladder pressure of these patients was highly correlated with the urine volume [4,32]. A wireless urine pot measuring device is ideal for such patients to keep a record, both indoors and outdoors. By looking at the stored data, patients understand more about the history of their catheterization volume and time period. At the same time, doctors can monitor and diagnose patients despite the distance. However, the system is not suitable for the patients with abnormal bladder function, such as abnormal bladder wall compliance caused by bladder fibrosis.

By way of face-to-face discussion by clinicians under IRB's ethical principles, the patients recruited in this study agreed that the system could effectively help them keep a record and make observations automatically. This was helpful in the bladder and urinary system care and meant the occurrence of 
UTIs could be decreased. The accessible lavatory function helped patients efficiently find a suitably accessible lavatory. By reducing the instance of holding urine, patients became more prepared for better social interactions. Based on the comments and scores given by experienced users, patients felt at ease to explore a new place without any psychological barrier.

A limitation of our system is that it is unable to detect the current volume of the bladder and give a catheter reminder, so the user is still troubled by drinking water, and must rely on time as the basis for catheterization. Besides this, the accessible lavatory function [29] can only be searched for its location and route navigation. A solution would be to combine a bladder monitor device and IoT device in this system. In the future, the proposed system will integrate a wearable device, capable of bladder volume estimation non-invasively, with a reminder function. Accessible lavatory navigator function with IoT device can calculate the state and the frequency of the toilet. Therefore, it can detect toilet crowdedness and prevent patients from holding urine for a long time. It is hoped that this system could improve the quality of life of patients and reduce the chance of UTIs. Equipping SCI patients with the above system enhances their sense of happiness and encourages them to enjoy outdoor-living by contacting the crowd.

Author Contributions: C.-M.H.: Designed the study and drafted the manuscript. Y.-C.D.: designed protocol and manuscript revision. J.-C.W.: Designed suggestion and revision. J.-J.J.C.: Conceived the study and revised the manuscript critically for intellectual content. J.-Y.C.: Designed the device and data analysis. All authors read and approved the final manuscript.

Funding: This study is funded by the Ministry of Science and Technology of Taiwan (MOST) (grant number 106-2218-E-384-001).

Acknowledgments: The authors would like to thank the nurses at the Chi Mei Medical Center who participated in this study.

Conflicts of Interest: The authors declare that they have no competing interests.

Ethics Approval and Consent to Participate: We obtained approval from the Ethics Committee of the Chi Mei Medical Center, Taiwan (10510-003) and written informed consent from each participant or his/her legal representative.

Consent for Publication: Not applicable.

Availability of Data and Material: The datasets used and/or analyzed during the current study are available from the corresponding author on reasonable request.

\section{Abbreviations}

NBD Neurogenic bladder dysfunction

UTIs Urinary tract infections

CIC Clean intermittent catheterization

SCI Spinal cord injury

CNS Central nervous system

IC Indwelling catheters

OPD Outpatient department

\section{References}

1. Lee, B.B.; Cripps, R.A.; Fitzharris, M.; Wing, P.C. The global map for traumatic spinal cord injury epidemiology: Update 2011, global incidence rate. Spinal Cord 2014, 52, 110-116. [CrossRef]

2. DeJong, G.; Tian, W.; Hsieh, C.H.; Junn, C.; Karam, C.; Ballard, P.H.; Smout, R.J.; Horn, S.D.; Zanca, J.M.; Heinemann, A.W.; et al. Rehospitalization in the first year of traumatic spinal cord injury after discharge from medical rehabilitation. Arch. Phys. Med. Rehabil. 2013, 94 (Suppl. 4), S87-S97. [CrossRef] [PubMed]

3. Cardenas, D.D.; Hoffman, J.M.; Kirshblum, S.; McKinley, W. Etiology and incidence of rehospitalization after traumatic spinal cord injury: A multicenter analysis. Arch. Phys. Med. Rehabil. 2004, 85, 1757-1763. [CrossRef] [PubMed]

4. Kershen Richard, T.; Azadzoi Kazem, M.; Siroky Mike, B. Blood Flow, Pressure and Compliance in the Male Human Bladder. J. Urol. 2002, 168, 121-125. [CrossRef] 
5. Krause, J.S.; Cao, Y.; DeVivo, M.J.; DiPiro, N.D. Risk and Protective Factors for Cause-Specific Mortality After Spinal Cord Injury. Arch. Phys. Med. Rehabil. 2016, 97, 1669-1678. [CrossRef] [PubMed]

6. Garcia-Arguello, L.Y.; O’Horo, J.C.; Farrell, A.; Blakney, R.; Sohail, M.R.; Evans, C.T.; Safdar, N. Infections in the spinal cord-injured population: A systematic review. Spinal Cord 2017, 55, 526-534. [CrossRef] [PubMed]

7. Lapides, J.; Diokno, A.C.; Silber, S.J.; Lowe, B.S. Clean, intermittent self-catheterization in the treatment of urinary tract disease. J. Urol. 1972, 107, 458-461. [CrossRef]

8. Shekelle, P.G.; Morton, S.C.; Clark, K.A.; Pathak, M.; Vickrey, B.G. Systematic review of risk factors for urinary tract infection in adults with spinal cord dysfunction. J. Spinal Cord Med. 1999, 22, 258-272. [CrossRef] [PubMed]

9. Massa, L.M.; Hoffman, J.M.; Cardenas, D.D. Validity, accuracy, and predictive value of urinary tract infection signs and symptoms in individuals with spinal cord injury on intermittent catheterization. J. Spinal Cord Med. 2009, 32, 568-573. [CrossRef]

10. Weld, K.J.; Graney, M.J.; Dmochowski, R.R. Differences in bladder compliance with time and associations of bladder management with compliance in spinal cord injured patients. J. Urol. 2000, 163, 1228-1233. [CrossRef]

11. Wu, J.; Miao, Y.; Abraham, S.N. The multiple antibacterial activities of the bladder epithelium. Ann. Transl. Med. 2017, 5, 35. [CrossRef] [PubMed]

12. Vaidyanathan, S.; Mansour, P.; Soni, B.M.; Singh, G.; Sett, P. The method of bladder drainage in spinal cord injury patients may influence the histological changes in the mucosa of neuropathic bladder-A hypothesis. Bmc Urol. 2002, 2, 5. [CrossRef]

13. Vasudeva, P.; Madersbacher, H. Factors implicated in pathogenesis of urinary tract infections in neurogenic bladders: Some revered, few forgotten, others ignored. Neurourol. Urodyn. 2014, 33, 95-100. [CrossRef] [PubMed]

14. Bartel, P.; Krebs, J.; Wollner, J.; Gocking, K.; Pannek, J. Bladder stones in patients with spinal cord injury: A long-term study. Spinal Cord 2014, 52, 295-297. [CrossRef] [PubMed]

15. Singh, R.; Rohilla, R.K.; Sangwan, K.; Siwach, R.; Magu, N.K.; Sangwan, S.S. Bladder management methods and urological complications in spinal cord injury patients. Indian J. Orthop. 2011, 45, 141-147. [CrossRef] [PubMed]

16. Taweel, W.A.; Seyam, R. Neurogenic bladder in spinal cord injury patients. Res. Rep. Urol. 2015, 7, 85-99. [CrossRef] [PubMed]

17. Vaidyanathan, S.; Mansour, P.; Ueno, M.; Yamazaki, K.; Wadhwa, M.; Soni, B.M.; Singh, G.; Hughes, P.L.; Watson, I.D.; Sett, P. Problems in early diagnosis of bladder cancer in a spinal cord injury patient: Report of a case of simultaneous production of granulocyte colony stimulating factor and parathyroid hormone-related protein by squamous cell carcinoma of urinary bladder. BMC Urol. 2002, 2, 8. [CrossRef]

18. Nassiff, A.; Mazzo, A.; Fumincelli, L.; Biaziolo, C.F.B.; Silva, D.R.A.; Meska, M.H.G. Voiding diary: Proposal and assessment of a tool. Int. J. Urol. Nurs. 2017, 11, 144-150. [CrossRef]

19. Ku, J.H.; Jeong, I.G.; Lim, D.J.; Byun, S.-S.; Paick, J.-S.; Oh, S.-J. Voiding diary for the evaluation of urinary incontinence and lower urinary tract symptoms: Prospective assessment of patient compliance and burden. Neurourol. Urodyn. 2004, 23, 331-335. [CrossRef] [PubMed]

20. Irgens, I.; Rekand, T. Telehealth for people with spinal cord injury: A narrative review. Spinal Cord 2018, 56, 643-655. [CrossRef]

21. Yuen, J.; Thiyagarajan, C.A.; Belci, M. Patient experience survey in telemedicine for spinal cord injury patients. Spinal Cord 2015, 53, 320-323. [CrossRef] [PubMed]

22. Craig, A.; Nicholson Perry, K.; Guest, R.; Tran, Y.; Dezarnaulds, A.; Hales, A.; Ephraums, C.; Middleton, J. Prospective study of the occurrence of psychological disorders and comorbidities after spinal cord injury. Arch. Phys. Med. Rehabil. 2015, 96, 1426-1434. [CrossRef] [PubMed]

23. Sweet, S.N.; Noreau, L.; Leblond, J.; Martin Ginis, K.A. Peer support need fulfillment among adults with spinal cord injury: Relationships with participation, life satisfaction and individual characteristics. Disabil. Rehabil. 2016, 38, 558-565. [CrossRef] [PubMed]

24. Pauwels, E.; De Wachter, S.; Wyndaele, J.J. Normality of bladder filling studied in symptom-free middle-aged women. J. Urol. 2004, 171, 1567-1570. [CrossRef] [PubMed]

25. Wyndaele, J.J.; De Wachter, S. Cystometrical sensory data from a normal population: Comparison of two groups of young healthy volunteers examined with 5 years interval. Eur. Urol. 2002, 42, 34-38. [CrossRef] 
26. Cheng, X.; Mei, X.; Hu, Y.; Fang, Y.; Wu, S.; You, F.; Kuang, S. Development of an E-Health App for Lower Limb Postoperative Rehabilitation Based on Plantar Pressure Analysis. Appl. Sci. 2018, 8, 766. [CrossRef]

27. Park, K.; Park, J.; Lee, J. An IoT System for Remote Monitoring of Patients at Home. Appl. Sci. 2017, 7, 260. [CrossRef]

28. Blaivas, J.G. The neurophysiology of micturition: A clinical study of 550 patients. J. Urol. 1982, 127, $958-963$. [CrossRef]

29. Wilde, M.H.; Brasch, J.; Zhang, Y. A qualitative descriptive study of self-management issues in people with long-term intermittent urinary catheters. J. Adv. Nurs. 2011, 67, 1254-1263. [CrossRef] [PubMed]

30. Bast, H.; Delling, D.; Goldberg, A.; Müller-Hannemann, M.; Pajor, T.; Sanders, P.; Wagner, D.; Werneck, R.F. Route Planning in Transportation Networks. In Algorithm Engineering; Kliemann, L., Sanders, P., Eds.; Springer: Cham, Switzerland, 2016; pp. 19-80.

31. Bao, Q.; Kochan, B.; Shen, Y.; Creemers, L.; Bellemans, T.; Janssens, D.; Wets, G. Applying FEATHERS for Travel Demand Analysis: Model Considerations. Appl. Sci. 2018, 8, 211. [CrossRef]

32. Harris, R.L.; Cundiff, G.W.; Theofrastous, J.P.; Bump, R.C. Bladder compliance in neurologically intact women. Neurourol. Urodyn. 1996, 15, 483-488. [CrossRef]

(C) 2019 by the authors. Licensee MDPI, Basel, Switzerland. This article is an open access article distributed under the terms and conditions of the Creative Commons Attribution (CC BY) license (http:/ / creativecommons.org/licenses/by/4.0/). 